\title{
A SIMULATION STUDY ON THE USES OF SHUTTLE CARRIERS IN THE CONTAINER YARD
}

\author{
Loo Hay Lee \\ Ek Peng Chew \\ Kok Choon Tan \\ Huei Chuen Huang \\ Wenquan Lin \\ Yongbin Han
}

Department of Industrial and Systems Engineering National University of Singapore, 10 Kent Ridge Crescent, Singapore 119260, SINGAPORE

\begin{abstract}
In this paper, we investigate how two main factors affect the efficiency of the port operation. The two main factors are type of transport vehicles and layout of the storage yard. Two different types of transport vehicles (i.e., prime mover and shuttle carrier) and two different types of layouts (i.e., with or without chassis lane beside the container blocks) are modeled in this study. A total of four simulation models are created to conduct this study. To evaluate the performance, the gross crane rate is used as the main performance measure, which is defined as the number of containers moved per quay crane per working hour. In this paper, it has been shown that the incorporation of the chassis lane improves the gross crane rate for both prime movers and shuttle carriers. The improvement is more substantial when the port utilizes shuttle carriers.
\end{abstract}

\section{INTRODUCTION}

In recent years, we have seen the disintegration of many trade barriers as a result of globalization. As such developments continue, there will be an increased focus in logistics and transportation, in particular the marine transportation. Evidently, the worldwide container trade has boomed $9.5 \%$ per year in the last decade, and it is projected to continue booming at $8 \%$ growth rate in the coming years. This inevitable trend will give rise to tremendous pressure for port operators to provide extremely efficient services to their clients as the repercussions of poor container terminal management can be extremely costly. All in all, an efficient, reliable global transportation system remains to be the backbone of an efficient global supply chain network.

In most ports today, prime movers or Automated Guided Vehicles (AGVs) are used to transfer containers

\author{
Tian Heong Chan
}

Group Technical \& Operations Development PSA International Pte Ltd $38^{\text {th }}$ Floor, PSA Building, 460 Alexandra Road Singapore 119963, SINGAPORE

between the quay side and the storage yard. For these vehicles, the quay cranes (QCs) and yard cranes (YCs) need to physically transfer the containers onto the vehicles, as these vehicles do not have the container-picking capability. As such, the QCs and YCs require the vehicles to be present before they are able to discharge or load the containers. This will result in redundant waiting time for the QCs, YCs and even the vehicles themselves.

In our simulation model, we investigate the uses of shuttle carrier (SHC) which has container-picking capabilities. A port in Europe is interested in the concept of using shuttle carriers in its port operation.

In this paper, we investigate the impact of different layouts and vehicles on the efficiency of the port operation. Two layouts are explored, one with a chassis lane incorporated between yard blocks and one without a chassis lane. For each layout, two types of vehicles, prime movers or shuttle carriers, are considered. Hence, a total of 4 different simulation models are constructed to assess the operations. A detailed problem definition is presented in section 3 .

\section{LITERATURE REVIEW}

As mentioned, the importance of efficient port operations cannot be underestimated. As such, port operation is a key research focus today. There are numerous papers covering a wide range of topics relevant to container terminal operations. Various decision support tools are built to ensure a smooth coordination of activities within the container terminal.

Among the decision support tools, simulation modeling is a powerful tool and often used to test alternative designs and explore possibilities before making investments in new resources or implementing new policies. For example, Kozan (1997) conducts a comparison between the 


\section{Lee, Chew, Tan, Huang, Lin, Han and Chan}

analytical and simulation planning models for a terminal. Yun and Choi (1999) also develop an object-oriented simulation model using SIMPLE++ to analyze the typical container terminal system in Pusan, Korea. Shabayek and Yeung (2002) build a simulation model using Witness to simulate the Kwai Chung container terminal in Hong Kong. A simulation model is developed by Sgouridis et al. (2003) to study the inbound container handling in an "All-Straddle-Carrier" System. In Yang et al. (2004), a simulation model is developed to analyze the effect of increasing the number of Automated Lifting Vehicles rather than Automated Guided Vehicles on the productivity of Automated Container Terminals.

In this paper, we also use a simulation-based approach to test the effects of the two factors on the efficiency of port operation. The simulation software used in the modeling is AutoMod v 11.0.

\section{PROBLEM DEFINITION}

This study is motivated by a port in Europe that is interested in the concept of using transport vehicles that can self-lift containers such as shuttle carriers. However, the port does not have a terminal which utilizes such equipments. As such, a simulation model is sought for investigating the efficiency and functionality of employing such equipments in a container port.

A total of 4 simulation models are created in this study. The models differ by 2 main factors:

- Layout of the port terminal, with chassis lanes or without chassis lanes

- Type of vehicles used, shuttle carriers or prime movers (PM)

Model 1 consists of a port layout without chassis lanes, and deploys prime movers as the container transport. Model 2 consists of a port layout with chassis lanes, and also deploys prime movers as the container transport. Model 3 consists of a port layout without chassis lanes but deploys shuttle carriers as the container transport. Model 4 consists of a port layout with chassis lanes, and also deploys shuttle carriers as the container transport.

Shuttle carriers can self-lift containers, while prime movers cannot. The biggest advantage of shuttle carriers over prime movers is that the quay crane and yard crane can continue to discharge or load containers even when the vehicles are not present at their side. Shuttle carriers can pick up containers at the allocated buffer areas, and transport the containers to their destinations, upon which the vehicles will drop the containers off at the designated buffer area. The quay cranes and yard cranes can discharge or load containers concurrently, as long as there are available buffer spaces for discharging of containers or there are containers in the buffer areas for loading. Hence, using shuttle carriers allows de-linking of operations between the quay cranes, yard cranes and the vehi- cles. However, this is not the case for prime movers, as they do not possess lifting capabilities. As such, the prime movers have to be around whenever the quay cranes and yard cranes load/discharge containers onto/from the prime movers.

Having chassis lanes in between the yard blocks allows the shuttle carriers to transport containers closer to the storage location (See Figure 1). This will reduce movements of the yard crane. If only front buffer is used, the yard crane will need to travel back to the front each time after dropping the previous containers. With the chassis lane, the yard crane will move directly to the next container placed beside the dropping spot.

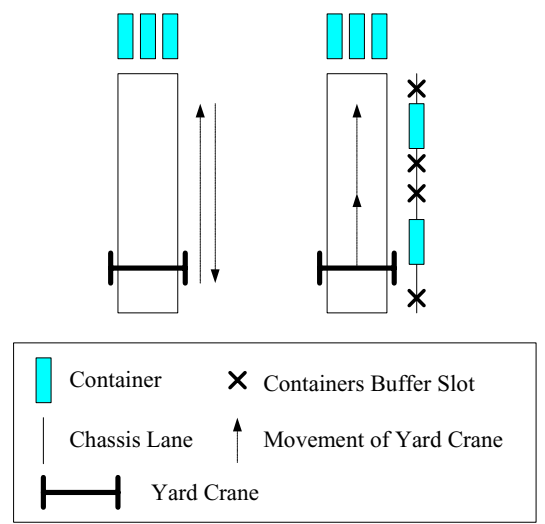

Figure 1: Movement of YC with and without Chassis Lane.

Note that only shuttle carriers can drop off containers at the chassis lanes. Prime movers are not able to drop off containers at the chassis lanes. Hence, prime movers have to wait in the chassis lane until it has been served by the yard crane. Another point to note is that containers placed at the chassis lanes will not block the movements of the shuttle carriers. This is so as shuttle carriers are able to carry containers up to 2 containers high, and hence can travel through a container on the ground while carrying a container.

While, on the surface, it may seem that the incorporation of the chassis lane will definitely improves the operations of the port, in reality that might not be the case. Incorporating the chassis lane reduces the yard storage space in the port, and this reduction might result in a shortage of yard storage space during times of heavy container traffic through the port. This would eventually cause congestion in the yard which in turn slows the operations.

As a first study in this area of research, we limit the scope of this study to discharging of containers from vessel only. Loading of containers from the yard to vessels is not considered in this study.

The objectives of this study are:

- Build 4 simulation models focusing on different factors, namely port layout and type of vehicles 


\section{Lee, Chew, Tan, Huang, Lin, Han and Chan}

used, that affect the operational efficiency of a port.

- Conduct an analysis to investigate the differences in efficiency between these factors.

\section{SIMULATION MODELING}

\subsection{Model Assumption}

The following are the assumptions made during the simulation modeling:

- Once a yard block is full, the block will be closed temporarily for housekeeping. Housekeeping will ensue until all the containers are cleared from the block. Upon which, the yard block will be open for use again.

- The quay cranes are assumed stationary or do not move much during the whole vessel operation.

- Quay buffer has a capacity of 4 containers for each quay crane. The front buffer at the yard block has a capacity of 3 containers. However, this is modeled as an input parameter that can be adjusted if necessary.

- Only one yard crane is deployed to serve each yard block. We do not implement the option of deploying a second yard crane during peak hours.

- The vessels are assumed to be berthed on a FirstCome-First-Serve basis.

- $\quad$ Each quay crane is allocated a number of vehicles dedicated to serve the quay crane. Once all containers are discharged by this quay crane, the vehicles will return to the parking area.

- Only 1 vehicle can be present in the chassis lane at any one time.

- Vehicles will always enter the chassis lane first if the chassis lane is available, i.e., no other vehicle is in the chassis lane.

\subsection{Description of the Simulation Models}

In this model, historical data are used to model the vessel arrival. When a vessel arrives, the vessel will first check if there is available berth space for the vessel to enter. If there is, the vessel will enter and claim the required number of quay cranes. Else, the vessel will wait until spaces are available to berth.

When the vessel enters the berth, a discharge list will be generated for each quay crane. Each quay crane will have an allocated number of containers to be discharged, which is specified in the historical data provided by the studied port. Each quay crane is also allocated a dedicated number of vehicles to transport containers from the quay crane to the yard blocks.
A list of yard locations is allocated to each quay crane for every vessel. Containers discharged by a specific quay crane will be transported to yard blocks that are only defined in the list for the quay crane. This is to model the real-world occurrence whereby containers discharged from a specific vessel will only go to a predefined list of yard blocks for the ease of tracking and retrieval. The number of yard locations assigned to each quay crane is one of the parameters in the simulation scenarios setup.

For model 1 and 2 (use prime movers), a quay crane will discharge a container only when a prime mover is present. For model 3 and 4 (use shuttle carriers), a quay crane will continue to discharge containers until the quay crane buffer space of 4 containers are completely used up. Shuttle carriers need not to be present. When all the containers allocated for the quay cranes are discharged, the quay crane will be free for use.

Containers discharged from the vessels will be transported by vehicles, either prime movers or shuttle carriers. The transport vehicles will carry the containers to the allocated yard blocks for storage. For prime movers, there is a $40 \%$ chance that a quay crane will discharge two containers to a single prime mover, and $60 \%$ chance that only one container discharged to the prime mover. For shuttle carriers, they will always pick up one container only.

The vehicles will first travel to the waiting point in front of the allocated yard block. For Model 2 and 4 whereby a chassis lane is present, the vehicle will first check if there is any other vehicle present in the chassis lane. If not, the vehicle will enter the chassis lane and transport the container to the side of the drop point in the yard block. Otherwise, the vehicle will travel to the front of the yard block. If there is no available space at the front buffer or at the chassis lane, the vehicle will continue to wait at the waiting point. For Model 1 and 2, only 1 prime mover can be present at the front of the yard block. The prime mover will also need to be present during the process that the yard crane picks up the container from the prime mover. For Model 3 and 4, there is a buffer space of 3 containers at the front of the yard blocks. Therefore, shuttle carriers will drop the containers at the front of the yard block until all 3 buffer slots are used up. After the containers are discharged from the vehicles, the vehicles will return to transfer any remaining containers from the quay to the yard. Once all containers are transported from the assigned quay crane, the vehicles will return to the parking point to wait for the next job.

When a yard crane picks up the container from the prime mover or from the buffer in front of the block, it will move to a random position in the yard and drop the container in the storage space. The depth of the gantry is a parameter to be set before simulation. If a chassis lane is present, the yard crane will pick up the nearest container after dropping the previous container in the yard block. 


\section{Lee, Chew, Tan, Huang, Lin, Han and Chan}

Otherwise, the yard crane will always travel back to the front of the yard block to pick up the next container.

When a yard block is full, it will be closed down for housekeeping. During this time, the yard crane will not be available for any new incoming vessels. For any quay cranes currently using this yard block, they will be allocated to a new yard block destination to discharge the containers to. When the housekeeping is completed, the yard block will be open for use to new incoming vessels.

When all the containers are discharged from the vessel, the vessel will leave the berth. The vessel will first wait for one hour to simulate the time required to exit the berth before the berth space is freed for other vessels to use. After the vessel leaves, the model will check through all the waiting vessels in an FCFS manner. All waiting vessels that can enter the newly freed space will enter the berth to be served.

\subsection{Proposed performance measure}

In this study, the gross crane rate (GCR) is used as the performance measure, which is defined as the total number of containers moved per quay crane per working hour.

$$
G C R=\frac{\text { Total number of containers moved }}{\text { Total working time (in hours) }}
$$

Total working time is defined as the total time a quay crane is claimed by vessels. It includes the idle time waiting for prime movers to return or the quay crane buffer to free up. However, it does not include the idle time when the quay crane is free and not claimed by any vessel.

\section{SIMULATION RESULTS AND ANALYSIS}

\subsection{Warm-up Analysis}

Based on the warm-up analysis experiment, a 60-day warm-up period is chosen for this simulation. The run length is chosen to be 60 days, so as to reduce the effect of initial bias.

\subsection{Scenario Setup}

Within each model, a total of 27 different scenarios are run. For each scenario, 5 replications are conducted. Using Intel ${ }^{\circledR}$ Pentium ${ }^{\circledR} 4$, CPU $2.80 \mathrm{GHz}, 512 \mathrm{MB}$ RAM. The scenarios differ by:

- Number of transport vehicles used

For models using prime movers, 3 different scenarios of 4,5 , and 6 prime movers are investigated. For models using shuttle carriers, 3 different scenarios of 3,4 , and 5 shuttle carriers are investigated.
- Depth of yard crane gantry

3 different scenarios of depth of 8,12 , and 16 containers are investigated.

- Yard crane to Quay crane ratio upon vessel arrival

3 different scenarios of 2.5, 3, and 3.5 yard cranes allocation are investigated. A 2.5 yard crane to quay crane ratio represents a $50 \%$ possibility that a quay crane is allocated to 2 yard cranes or 3 yard cranes (similarly for 3.5).

We use a standard notation of [Number of transport vehicles, Depth of yard crane gantry, Yard crane to Quay crane ratio] (e.g. $[4,12,3.5])$ to describe the scenario for the rest of the paper.

\subsection{Within model analysis - Model 1 (Prime mover, without chassis lane)}

The mean GCRs from model 1 for each of the 27 scenarios are shown in Table 1.

Table 1: Mean values of the Mean Gross Crane Rate for model 1.

\begin{tabular}{cccc}
\hline & \multicolumn{3}{c}{ Depth of gantry = 8 } \\
\hline & $\mathbf{2 . 5}$ & $\mathbf{3}$ & $\mathbf{3 . 5}$ \\
\hline 4 PM & 28.40 & 29.68 & 30.29 \\
5 PM & 29.31 & 30.53 & 31.14 \\
6 PM & 29.77 & 31.26 & 31.89 \\
\hline \multicolumn{4}{c}{ Depth of gantry = 12 } \\
\hline 2.5 & $\mathbf{3}$ & $\mathbf{3 . 5}$ \\
\hline 4 PM & 26.36 & 27.99 & 28.44 \\
5 PM & 27.29 & 28.77 & 29.77 \\
6 PM & 27.90 & 29.46 & 30.21 \\
\hline \multicolumn{4}{c}{ Depth of gantry $=16$} \\
\hline 4 PM & 24.5 & $\mathbf{3}$ & $\mathbf{3 . 5}$ \\
\hline 5 PM & 25.41 & 26.07 & 26.84 \\
6 PM & 25.95 & 27.86 & 28.09 \\
\hline
\end{tabular}

The confidence intervals (C.I.) of GCR from model 1 for each of the 27 scenarios are shown in Table 2.

Table 2: 95\% Confidence Intervals of Mean Gross Crane Rate for model 1.

\begin{tabular}{cccc}
\hline & \multicolumn{3}{c}{ Depth of gantry = 8 } \\
\hline & $\mathbf{2 . 5}$ & $\mathbf{3}$ & $\mathbf{3 . 5}$ \\
\hline \multirow{2}{*}{ 4 PM } & $(28.33$, & $(29.59$, & $(30.20$, \\
& $28.47)$ & $29.78)$ & $30.38)$ \\
\multirow{4}{*}{ 5 PM } & $(29.17$, & $(30.47$, & $(31.03$, \\
& $29.45)$ & $30.58)$ & $31.25)$ \\
6 PM & $(29.65$, & $(31.11$, & $(31.77$, \\
& $29.89)$ & $31.41)$ & $32.01)$ \\
\hline
\end{tabular}


Lee, Chew, Tan, Huang, Lin, Han and Chan

\begin{tabular}{cccc}
\hline \multicolumn{4}{c}{ Depth of gantry = 12 } \\
\hline & $\mathbf{2 . 5}$ & $\mathbf{3}$ & $\mathbf{3 . 5}$ \\
\hline \multirow{2}{*}{ 4 PM } & $(26.18$, & $(27.89$, & $(28.28$, \\
& $26.54)$ & $28.10)$ & $28.61)$ \\
5 PM & $(27.14$, & $(28.61$, & $(29.62$, \\
& $27.45)$ & $29.94)$ & $29.91)$ \\
6 PM & $(27.73$, & $(29.28$, & $(30.03$, \\
& $28.07)$ & $29.64)$ & $30.40)$ \\
\hline \multicolumn{4}{c}{ Depth of gantry = 16 } \\
\hline \multirow{4}{*}{ 2.5 } & $\mathbf{3}$ & $\mathbf{3 . 5}$ \\
\hline \multirow{4}{*}{ PM } & $(24.40$, & $(25.96$, & $(26.73$, \\
& $24.83)$ & $26.18)$ & $26.95)$ \\
& $(25.23$, & $(27.15$, & $(27.98$, \\
6 PM & $25.58)$ & $27.64)$ & $28.20)$ \\
& $(25.76$, & $(27.67$, & $(28.49$, \\
& $26.13)$ & $28.05)$ & $28.98)$ \\
\hline
\end{tabular}

From the results shown in Table 1 and Table 2, the scenario of $[6,8,3.5]$ gives the best results among other scenarios. As the C.I. of this scenario does not overlap with any other C.I., it is shown that there is a significant difference between the results at $95 \%$ confidence level.

Figure 2, Figure 3, and Figure 4 show the results in graphic format. It can be seen that the GCR increases when the number of vehicles and the yard to quay crane ratio increases. From the C.I., it is shown that these factors affect the response significantly.

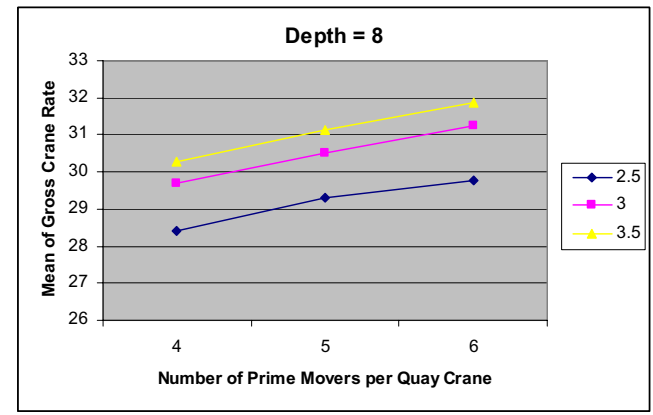

Figure 2: Graphic representation of model 1 results $($ depth=8).

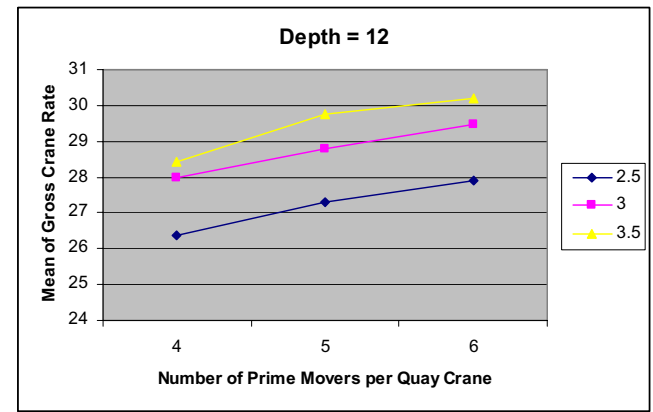

Figure 3: Graphic representation of model 1 results (depth=12).

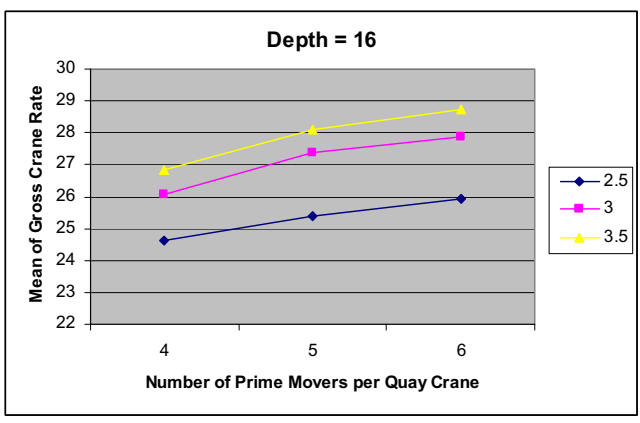

Figure 4: Graphic representation of model 1 results (depth=16).

It is unsurprising that an increase in the number of vehicles improves the GCR. With more vehicles, there will be less waiting for the quay cranes and the yard cranes to operate. However, the incremental improvement in GCR will diminish due to the increase in traffic congestions and more frequent waiting of the vehicles to be served by the quay cranes and yard cranes occasionally. The upward turning of the curves reveals that the increase in GCR is reduced. However, it should be noted that, from Figure 2, there is no upward curving for 3 and 3.5 lines when the depth of gantry is 8 . This is because the yard crane's cycle time is short due to the shorter depth of gantry. Hence, yard crane is not the bottlenecking factor in this case. Increasing the number of vehicles running in the port is likely to increase the GCR.

With a higher yard to quay crane ratio, there will be more yard cranes to stack the containers. There will also be more buffer points for the vehicles to discharge containers, and thereby reducing congestion and wait time at the yard side. This is especially vital when the number of vehicles is high. We see that the increase in GCR is reduced when we increase the number of vehicles running without a corresponding increase in the yard to quay crane ratio. When the ratio increases, the cycle time of prime movers between the yard and the quay crane will be shortened. This will in turn improve the GCR.

It can be seen that the shorter the depth of gantry, the higher the GCR. It is because allowing deeper gantry means that yard cranes will travel a longer distance to discharge containers frequently. This increase in traveling distance increases the cycle time of the yard crane significantly (see Table 3 ).

Table 3: Cycle times of yard crane (in seconds) for model 1.

\begin{tabular}{ccc}
\hline Depth = 8 & Depth = 12 & Depth = 16 \\
\hline 133.4 & 144.4 & 156.5
\end{tabular}




\subsection{Within model analysis - Model 2 (Prime mover, with chassis lane)}

The means and confidence intervals of GCR from model 2 for each of the 27 scenarios are shown in Table 4 and Table 5. The cycle time of yard crane from model 3 is shown in Table 6.

Table 4: Mean values of the Mean Gross Crane Rate for model 2 .

\begin{tabular}{|c|c|c|c|}
\hline & \multicolumn{3}{|c|}{ Depth of gantry $=8$} \\
\hline & 2.5 & 3 & 3.5 \\
\hline 4 PM & 29.96 & 31.10 & 31.43 \\
\hline 5 PM & 30.52 & 31.84 & 32.30 \\
\hline \multirow[t]{3}{*}{6 PM } & 31.15 & 32.46 & 32.82 \\
\hline & \multicolumn{3}{|c|}{ Depth of gantry = 12} \\
\hline & 2.5 & 3 & 3.5 \\
\hline 4 PM & 28.52 & 29.63 & 30.34 \\
\hline 5 PM & 29.35 & 30.75 & 31.21 \\
\hline \multirow[t]{3}{*}{6 PM } & 29.75 & 31.28 & 31.93 \\
\hline & \multicolumn{3}{|c|}{ Depth of gantry $=16$} \\
\hline & 2.5 & 3 & 3.5 \\
\hline 4 PM & 27.35 & 28.85 & 29.23 \\
\hline 5 PM & 28.06 & 29.69 & 30.68 \\
\hline 6 PM & 28.72 & 30.43 & 31.61 \\
\hline
\end{tabular}

Table 5: 95\% Confidence Intervals of Mean Gross Crane Rate for model 2.

\begin{tabular}{|c|c|c|c|}
\hline & \multicolumn{3}{|c|}{ Depth of gantry $=8$} \\
\hline & 2.5 & 3 & 3.5 \\
\hline PM & $\begin{array}{l}(2 \\
3\end{array}$ & 31. & $\begin{array}{l}31, \\
55)\end{array}$ \\
\hline & $\begin{array}{c}(30.43 \\
30.61)\end{array}$ & $\begin{array}{l}(31 \\
31 .\end{array}$ & $\begin{array}{l}(32.20, \\
32.40)\end{array}$ \\
\hline 6 PM & $\begin{array}{l}(31.04 \\
31.26) \\
\end{array}$ & $\begin{array}{c}(32.38 \\
32.55)\end{array}$ & $\begin{array}{l}(32.71, \\
32.94)\end{array}$ \\
\hline \multicolumn{4}{|c|}{ Depth of gantry = 12} \\
\hline & 2.5 & 3 & 3.5 \\
\hline & $\begin{array}{l}(28.41 \\
28.64)\end{array}$ & 6) & $\begin{array}{l}(30.22, \\
30.45)\end{array}$ \\
\hline 5 & & & $\begin{array}{l}(31.11, \\
31.31)\end{array}$ \\
\hline & $\begin{array}{l}(29.62 \\
29.88)\end{array}$ & $\begin{array}{l}(31.20 \\
31.37)\end{array}$ & $\begin{array}{l}(31.82, \\
31.05)\end{array}$ \\
\hline & \multicolumn{3}{|c|}{ Depth of gantry $=16$} \\
\hline & 2.5 & 3 & 3.5 \\
\hline & $\begin{array}{l}(27.21 \\
27.48)\end{array}$ & $\begin{array}{l}(28.74 \\
28.96)\end{array}$ & $\begin{array}{l}(29.17, \\
29.29)\end{array}$ \\
\hline 5 & $\begin{array}{l}(27.87 \\
28.25)\end{array}$ & $\begin{array}{l}(29 . \\
29 .\end{array}$ & $\begin{array}{l}(30.61, \\
30.75)\end{array}$ \\
\hline $6 \mathrm{P}$ & $\begin{array}{l}(28.53 \\
28.92)\end{array}$ & $\begin{array}{c}(30.26 \\
30.60)\end{array}$ & $\begin{array}{l}(31.51, \\
31.70)\end{array}$ \\
\hline
\end{tabular}

Table 6: Cycle times of yard crane (in seconds) for model 2.

\begin{tabular}{ccc}
\hline Depth = 8 & Depth = 12 & Depth = 16 \\
\hline 128.9 & 136.3 & 145.9 \\
\hline
\end{tabular}

The results are similar to those from model 1. It can be seen that the same scenario gives the best result for the mean gross crane rate.

\subsection{Between model analysis - Model 1 and 2}

From the results of the model 1 and model 2 , it can be seen that the mean GCR of model 2 is higher than the mean GCR of model 1 for all cases. Comparing the C.I. of the results of the best scenario $[6,8,(3,4)]$, we can see that the mean GCRs from the 2 models are statistically different, with a mean improvement of $2.92 \%$.

With the incorporation of the chassis lane, the vehicles will occasionally need to travel further. However, as the speed of the transport vehicles is much higher than the speed of yard crane, it makes more sense for the vehicles to cover the extra distance instead of the yard crane. Moreover, the vehicles can travel to a serving point closer to the container's drop point in the yard while the yard crane is simultaneously handling other containers. The chassis lane also provides extra serving points for the vehicles, thereby reducing congestions and competition among the vehicles compared to the previous model. This improves the potential of allocating more vehicles into the port to increase the GCR. The reduction in the redundant movements of the yard crane also reduces yard crane cycle time, thereby improving the rate of the yard crane service.

The incorporation of the chassis lane has a greater improvement in the GCR when the depth of the gantry is higher. This is because the yard crane would generally need to travel a longer distance when the depth of gantry is higher, and the incorporation of the chassis lane provides a larger saving in this case.

As can be seen from Table 7, the GCR has improved consistently for all scenarios when chassis lanes are incorporated into the port layout. This shows that the yard crane is the more critical constraint compared to space availability.

Table 7: Yard crane cycle time improvement (Model 1 to Model 2).

\begin{tabular}{lccc}
\hline & Depth = 8 & Depth = 12 & Depth = 16 \\
\hline Model 1 & $133.4 \mathrm{sec}$ & $144.4 \mathrm{sec}$ & $156.5 \mathrm{sec}$ \\
Model 2 & $128.9 \mathrm{sec}$ & $136.3 \mathrm{sec}$ & $145.9 \mathrm{sec}$ \\
Change & $4.5 \mathrm{sec}$ & $8.1 \mathrm{sec}$ & $10.6 \mathrm{sec}$ \\
\% chg. & $3.39 \%$ & $5.61 \%$ & $6.80 \%$ \\
\hline
\end{tabular}




\subsection{Within model analysis - Model 3 (Shuttle Carrier, without chassis lane)}

The means and confidence intervals of GCR from model 3 for each of the 27 scenarios are shown in Table 8 and Table 9. The cycle time of yard crane from model 3 is shown in Table 10.

Table 8: Mean values of the Mean Gross Crane Rate for model 3 .

\begin{tabular}{|c|c|c|c|}
\hline & \multicolumn{3}{|c|}{ Depth of gantry $=8$} \\
\hline & 2.5 & 3 & 3.5 \\
\hline 4 PM & 29.23 & 30.71 & 31.42 \\
\hline 5 PM & 29.76 & 31.50 & 32.26 \\
\hline \multirow[t]{3}{*}{6 PM } & 30.13 & 31.90 & 32.75 \\
\hline & \multicolumn{3}{|c|}{ Depth of gantry = 12} \\
\hline & 2.5 & 3 & 3.5 \\
\hline 4 PM & 27.17 & 28.85 & 29.87 \\
\hline 5 PM & 27.75 & 29.57 & 30.56 \\
\hline \multirow[t]{3}{*}{6 PM } & 28.11 & 30.12 & 30.87 \\
\hline & \multicolumn{3}{|c|}{ Depth of gantry $=16$} \\
\hline & 2.5 & 3 & 3.5 \\
\hline 4 PM & 25.09 & 27.20 & 28.06 \\
\hline 5 PM & 25.76 & 27.84 & 28.94 \\
\hline 6 PM & 26.08 & 28.32 & 29.40 \\
\hline
\end{tabular}

Table 9: 95\% Confidence Intervals of Mean Gross Crane Rate for model 3.

\begin{tabular}{|c|c|c|c|}
\hline & \multicolumn{3}{|c|}{ Depth of gantry $=8$} \\
\hline & 2.5 & 3 & 3.5 \\
\hline 4 PM & $\begin{array}{l}(29.02 \\
29.44)\end{array}$ & $\begin{array}{l}(30.56, \\
30.86)\end{array}$ & $\begin{array}{l}(31.20, \\
31.64)\end{array}$ \\
\hline 5 PM & $\begin{array}{l}(29.62 \\
29.90)\end{array}$ & $\begin{array}{l}(31.35, \\
31.65)\end{array}$ & $\begin{array}{l}(32.14, \\
32.37)\end{array}$ \\
\hline 6 PM & $\begin{array}{l}(30.00 \\
30.26)\end{array}$ & $\begin{array}{l}(31.69, \\
32.11)\end{array}$ & $\begin{array}{l}(32.68, \\
32.83)\end{array}$ \\
\hline \multicolumn{4}{|c|}{ Depth of gantry $=12$} \\
\hline & 2.5 & 3 & 3.5 \\
\hline 4 & $\begin{array}{l}(26.93 \\
27.42)\end{array}$ & $\begin{array}{l}(28.72, \\
28.98)\end{array}$ & $\begin{array}{l}(29.67, \\
30.07)\end{array}$ \\
\hline 5 & $\begin{array}{l}(27.55 \\
27.96)\end{array}$ & $\begin{array}{l}(29.40, \\
29.75)\end{array}$ & $\begin{array}{l}(30.33, \\
30.79)\end{array}$ \\
\hline 6 PM & $\begin{array}{l}(28.01 \\
28.20)\end{array}$ & $\begin{array}{l}(29.98 \\
30.27)\end{array}$ & $\begin{array}{l}(30.64, \\
31.10)\end{array}$ \\
\hline & \multicolumn{3}{|c|}{ Depth of gantry $=16$} \\
\hline & 2.5 & 3 & 3.5 \\
\hline $4 P$ & $\begin{array}{l}(24.92 \\
25.26)\end{array}$ & $\begin{array}{l}(26.98, \\
27.41)\end{array}$ & $\begin{array}{l}(27.90, \\
28.23)\end{array}$ \\
\hline $5 \mathrm{PN}$ & $\begin{array}{l}(25.61 \\
25.90)\end{array}$ & $\begin{array}{l}(27.62, \\
28.06)\end{array}$ & $\begin{array}{l}(28.73, \\
29.16)\end{array}$ \\
\hline $6 \mathrm{P}$ & $\begin{array}{l}(25.93 \\
26.23)\end{array}$ & $\begin{array}{l}(28.24, \\
28.40)\end{array}$ & $\begin{array}{l}(29.26, \\
29.54)\end{array}$ \\
\hline
\end{tabular}

Table 10: Cycle times of yard crane (in seconds) for model 3.

\begin{tabular}{ccc}
\hline Depth = 8 & Depth = 12 & Depth = 16 \\
\hline 134.5 & 145.0 & 155.7 \\
\hline
\end{tabular}

From the results shown above, we can see that compared to using prime movers, using shuttle carriers improves the GCR. Comparing to Model 1, we can see that using the same number of vehicles in Model 3, which utilizes shuttle carriers, gives a higher gross crane rate for all cases. Generally, results from Model 3 are comparable to results from Model 1 even when the number of vehicles is reduced by 1 .

As shuttle carriers have container pick-up and dropdown capabilities, the vehicles need not be present when quay/yard crane operates. This improves the general turnaround time of the vehicles traveling between the yard and the quay, as the vehicles do not need to wait for the quay and yard crane operation. Moreover, the quay crane can continue to discharge containers until the quay side buffer are filled up. The functionalities of the shuttle carriers also allow buffer spaces to be set up at the quay and yard crane area. The buffer spaces at the quay side allow 2 shuttle carriers to pick up containers simultaneously at the same time, whereas previously the quay crane can only discharge to one prime mover at a time. The buffer space of 3 containers at the yard also reduces the waiting time of shuttle carriers for yard crane service significantly. These result in an additional improvement in the turnaround time of the shuttle carriers.

\subsection{Within model analysis - Model 4 (Shuttle Carrier, with chassis lane)}

The means and confidence intervals of GCR from model 4 for each of the 27 scenarios are shown in Table 11 and Table 12. The cycle time of yard crane from model 4 is shown in Table 13. It can be seen that Model 4 gives a substantial improvement as compared to the other models.

Table 11: Mean values of the Mean Gross Crane Rate for model 4.

\begin{tabular}{|c|c|c|c|}
\hline & \multicolumn{3}{|c|}{ Depth of gantry = 8} \\
\hline & 2.5 & 3 & 3.5 \\
\hline 4 PM & 32.49 & 33.56 & 34.11 \\
\hline 5 PM & 33.21 & 34.02 & 34.62 \\
\hline \multirow[t]{3}{*}{6 PM } & 33.52 & 34.39 & 34.85 \\
\hline & \multicolumn{3}{|c|}{ Depth of gantry = 12} \\
\hline & 2.5 & 3 & 3.5 \\
\hline $4 \mathrm{PM}$ & 31.73 & 33.02 & 33.79 \\
\hline 5 PM & 32.38 & 33.49 & 34.26 \\
\hline \multirow[t]{3}{*}{6 PM } & 32.70 & 33.76 & 34.49 \\
\hline & \multicolumn{3}{|c|}{ Depth of gantry $=16$} \\
\hline & 2.5 & 3 & 3.5 \\
\hline
\end{tabular}




\begin{tabular}{llll}
\hline 4 PM & 31.29 & 32.45 & 33.42 \\
5 PM & 31.90 & 33.09 & 33.82 \\
6 PM & 32.33 & 33.42 & 33.97 \\
\hline
\end{tabular}

Table 12: 95\% Confidence Intervals of Mean Gross Crane Rate for model 4.

\begin{tabular}{|c|c|c|c|}
\hline & \multicolumn{3}{|c|}{ Depth of gantry $=8$} \\
\hline & 2.5 & 3 & 3.5 \\
\hline 4 PM & $\begin{array}{l}(32.33 \\
32.65)\end{array}$ & $\begin{array}{l}(33.42, \\
33.69)\end{array}$ & $\begin{array}{l}(33.92, \\
34.30)\end{array}$ \\
\hline 5 PM & $\begin{array}{l}(33.08 \\
33.34)\end{array}$ & $\begin{array}{l}(33.92, \\
34.13)\end{array}$ & $\begin{array}{l}(34.48, \\
34.73)\end{array}$ \\
\hline 6 PM & $\begin{array}{c}(33.36 \\
33.69)\end{array}$ & $\begin{array}{l}(34.16, \\
34.62)\end{array}$ & $\begin{array}{c}(34.75, \\
34.97)\end{array}$ \\
\hline & \multicolumn{3}{|c|}{ Depth of gantry $=12$} \\
\hline & 2.5 & 3 & 3.5 \\
\hline 4 PM & $\begin{array}{l}(31.51 \\
31.94)\end{array}$ & $\begin{array}{l}(32.92, \\
33.13)\end{array}$ & $\begin{array}{l}(33.60, \\
33.97)\end{array}$ \\
\hline 5 PM & $\begin{array}{l}(32.21 \\
32.54)\end{array}$ & $\begin{array}{l}(33.36, \\
33.62)\end{array}$ & $\begin{array}{l}(34.02, \\
34.50)\end{array}$ \\
\hline 6 PM & $\begin{array}{c}(32.59 \\
32.82)\end{array}$ & $\begin{array}{l}(33.64, \\
33.88)\end{array}$ & $\begin{array}{l}(34.27, \\
34.70)\end{array}$ \\
\hline & \multicolumn{3}{|c|}{ Depth of gantry $=16$} \\
\hline & 2.5 & 3 & 3.5 \\
\hline 4 PM & $\begin{array}{l}\text { (31.11, } \\
31.46)\end{array}$ & $\begin{array}{l}(32.29, \\
32.62)\end{array}$ & $\begin{array}{l}(33.31, \\
33.54)\end{array}$ \\
\hline 5 PM & $\begin{array}{c}(31.73 \\
32.07)\end{array}$ & $\begin{array}{l}(32.98, \\
33.21)\end{array}$ & $\begin{array}{l}(33.62, \\
34.02)\end{array}$ \\
\hline 6 PM & $\begin{array}{c}(32.22 \\
32.45)\end{array}$ & $\begin{array}{l}(33.35, \\
33.50)\end{array}$ & $\begin{array}{l}(33.81, \\
34.13)\end{array}$ \\
\hline
\end{tabular}

Table 13: Cycle times of yard cranes (in seconds) for model 4

\begin{tabular}{ccc}
\hline Depth = 8 & Depth = 12 & Depth = 16 \\
\hline 121.47 & 126.79 & 132.43 \\
\hline
\end{tabular}

\subsection{Between model analysis - Model 2 and 4}

From the simulation results, it is shown that the incorporation of chassis lanes gives a substantial improvement when the port utilizes shuttle carriers instead of prime movers. When using the prime movers, the benefits of the chassis lanes are not exploited fully. As only 1 vehicle is allowed to be present in the chassis lane at one time, prime movers cannot enter the chassis lane when the yard crane is serving another prime mover currently positioned in the chassis lane.

However, as shuttle carriers can drop off containers independently, they turnaround faster in the chassis lanes. This will allow more shuttle carriers to enter, and hence more buffer slots can be used to place containers waiting to be moved into the yard block. Comparatively, only one buffer slot will be utilized when prime movers are used. As a result, there will be less waiting for shuttle carriers at the yard, and more containers can be transferred from the quay to the yard quickly, thereby increasing the gross quay crane rate.

Moreover, we see from Table 14 that the yard crane cycle time is further reduced in Model 4. This is also a consequence of the utilization of more buffer slots in the chassis lane. As there can only be 1 prime mover in the chassis lane at one time, the yard crane will normally return to pick up the container at the front after serving the prime mover in the chassis lane. However, in the case of using shuttle carriers, there are often a few containers at the chassis lane buffers. Hence, after dropping one container, the yard crane will move to pick up the next nearest container. Therefore, the cycle time of the yard crane in model 4 will be lower than that in model 2. This increases the service rate of the yard crane and improves the gross crane rate of the quay crane.

Table 14: Yard crane cycle time improvement (Model 2 to Model 4).

\begin{tabular}{lccc}
\hline & Depth = 8 & Depth = 12 & Depth = 16 \\
\hline Model 2 & $128.9 \mathrm{sec}$ & $136.3 \mathrm{sec}$ & $145.9 \mathrm{sec}$ \\
Model 4 & $121.5 \mathrm{sec}$ & $126.8 \mathrm{sec}$ & $132.4 \mathrm{sec}$ \\
Change & $7.4 \mathrm{sec}$ & $9.5 \mathrm{sec}$ & $13.5 \mathrm{sec}$ \\
\% chg. & $5.73 \%$ & $7.00 \%$ & $9.23 \%$ \\
\hline
\end{tabular}

\section{CONCLUSION AND FUTURE RESEARCH}

\subsection{Conclusion}

In this study, we have adopted a simulation approach to investigate how the utilization of different layouts and vehicles affect the port operation. From the simulation results, it has shown that the incorporation of the chassis lanes improves the gross crane rate. In addition, using shuttle carriers in a chassis lane layout gives a greater improvement than using prime movers. Shuttle carriers maximize the benefits of the chassis lanes as they are able to handle containers independently. The study also shows that the yard crane is a more critical constraint than space availability, as incorporating chassis lanes has improved the gross crane rate even with a reduction in the storage space.

\subsection{Future Directions}

In this study, we have assumed that vehicles perform dedicated service to quay cranes. However, this assumption can be relaxed to full share service by allowing vehicles to perform service to other quay cranes when they are idle. 
The simulation models have only considered discharging containers from vessels only. Loading containers from the yard to the quay can be modeled to investigate the interaction of traffic and yard cranes in the reverse direction. Moreover, we have not considered external vehicles picking up containers from the yard to the inland. These operations might affect the frequency of housekeeping of the yard. In our model, we have modeled that the housekeeping of the yard block is performed only when the yard block is closed.

A higher throughput can also be used to test the constraint in the yard storage space.

\section{REFERENCES}

Kozan, E. 1997. Comparison of analytical and simulation planning models of seaport container terminals. Transportation Planning and Technology 20(3):235248.

Sgouridis, S. P., D. Makris, and D. C. Angelides. 2003. Simulation analysis for midterm yard planning in container terminal. Journal of Waterway, Port, Coastal and Ocean Engineering 129(4):178-187.

Shabayek, A. A., and W. W. Yeung. 2002. A simulation model for the Kwai Chung container terminals in Hong Kong. European Journal of Operational Research 140:1-11.

Yang, C. H., Y. S. Choi, and T. Y. Ha. 2004. Simulationbased performance evaluation of transport vehicles at automated container terminals. OR Spectrum 26:149170.

Yun, W. Y., and Y. S. Choi. 1999. A simulation model for container-terminal operation analysis using an object-oriented approach. International journal of Production Economics 59(1-3):221-230.

\section{AUTHOR BIOGRAPHIES}

LOO HAY LEE is an associate professor in the department of Industrial and Systems Engineering at National University of Singapore. His research interest lies in the area of production planning and control, logistics and vehicle routing, supply chain modeling, simulation-based optimization, ordinary optimization, and evolutionary computation. His web page can be found via $<$ http://www.ise.nus.edu.sg/staff/leelh/index.html $>$.

EK PENG CHEW is an associate professor in the department of Industrial and Systems Engineering at National University of Singapore. His research interests include logistics and inventory management, system modeling and optimization, analysis of order picking systems, and optimization. His web page can be found via $<$ http://www.ise.nus.edu.sg/staff/chewep/index.html $>$.
KOK CHOON TAN is an adjunct associate professor in the department of Industrial and Systems Engineering at National University of Singapore. His research interests include container port operations research, urban OR applications in transportation, queuing applications, optimization theory and applications, and logistics. His web page can be found via $<$ http://www.ise.nus.edu.sg/staff/TanKokChoon/index.ht $\mathrm{ml}>$.

WENQUAN LIN is an undergraduate student in the department of Industrial and Systems Engineering at National University of Singapore.

YONGBIN HAN is a research fellow in the department of Industrial and Systems Engineering at National University of Singapore. His research interest lies in the area of simulation and optimization in port operations. His web page can be found via $<$ http://www.ise.nus.edu.sg/research_students/photos/nam e.php?id=19>.

CHAN TIAN HEONG is deputy manager at Group Technical and Operations Development, PSA involved in developing and evaluating future operating concepts for container terminals. 